\title{
Comparison between primary closure and T-tube drainage after open choledochotomy
}

\author{
Hamed H Abosteit, MD MRCS; Ahmed M Kamal, MD; \\ Mostafa F Abdellatif, MD
}

\author{
Department of General Surgery, Ain Shams University, Cairo, Egypt.
}

\begin{abstract}
Background: Choledochotomy followed by T-tube drainage has been long the standard surgical treatment in many hospitals. However, the insertion of a T-tube is not without complications and the patients have to carry it for 2 weeks before removal. To avoid those complications associated with T-tube, we have performed primary closure of the common bile duct (CBD) after choledochotomy and removal of CBD stones. This study assesses the safety of primary closure of $C B D$ and may help in its application in a wide scale.

Objectives: To compare the clinical results of primary closure of $(C B D)$ with $T$-tube drainage after open choledochotomy.

Patients \& methods: This comparative study was conducted at El-Demerdash Hospital \& Ain Shams University Hospital from January 2008 to December 2008. Thirty patients were included in the study, 15 patients underwent primary closure and 15 patients underwent T-tube drainage.

Results: There was no mortality in both groups. A T-tube was inserted in 15 patients and the $C B D$ was closed primarily in 15 patients, there were no difference in the demographic characteristics or clinical presentations between the two groups. Compared with the T-tube group, the post-operative stay was significantly shorter, the hospital expenses significantly lower, and the incidences of overall postoperative complications and biliary complications were statistically and significantly lower in the primary closure group.

Conclusion: Primary closure without external drainage after open choledochotomy is feasible and as safe as T-tube insertion.
\end{abstract}

\section{Introduction:}

Common bile duct (CBD) stones are the most frequent complications of gall stones and occurs in $10 \%$ to $15 \%$ of patients. ${ }^{1,2}$

Traditionally, the CBD is closed with Ttube drainage after choledochotomy and removal of CBD stones. However, T-tube usage is not without morbidity ${ }^{3,4}$ The most frequent of these is bile leakage after removal, which is reported to occur in $1-19 \%$ of cases and tract infection. ${ }^{3-5}$

In addition, having bile drainage in place of several weeks before removal causes significant discomfort to patients and delays their return to work. 6,7

The disadvantages led several authors to perform primary closure after choledochotomy with the help of intra-operative cholangiogram and direct visualization of the CBD. So, retained stones are not a problem. ${ }^{8-10}$

\section{Patients and methods:}

This comparative study was conducted at surgical unit in El-Demerdash Hospital and Ain Shams Specialized Hospital.

Thirty patients were admitted in the year 2008 were included in this study. All patients were evaluated with routine investigations including full blood counts, liver function tests, coagulation profile and abdominal ultrasonography. The criteria for choledochotomy were calcular obstructive jaundice. All patients were given $1 \mathrm{gm}$ cefotaxime IV one hour preoperatively. 


\section{Surgical Procedures:}

The CBD was opened through a supraduodenal vertical incision between two stay sutures. Stones were taken out followed by flushing with saline to ensure patency. We confirmed the clearance of the duct by intraoperative cholangiogram then primary closure of the CBD was performed in 15 patients. Patients were randomly selected to undergo either one of the two surgical options, primary closure of CBD and T-tube drainage then interrupted 4/0 vicryl sutures were applied.
In 15 patients, T-tube was inserted into the CBD.

At the end of the procedure, a single infrahepatic suction drain was placed, and this was removed after 48-96 hours if there was no bile leak. Patients who had a T-tube inserted had a cholangiogram on the 10th post-operative day and if this was normal the T-tube was clamped and removed from 10th-14th day.

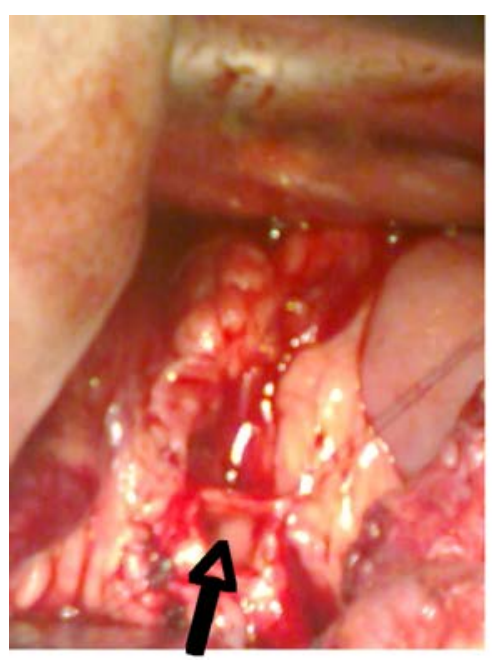

Open Choledochotomy

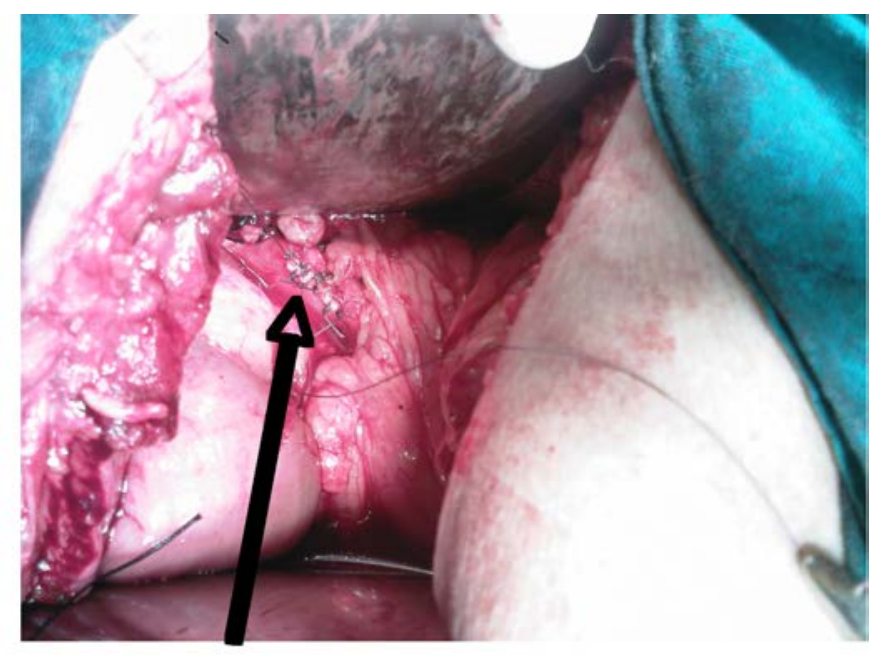

Primary closure of CBD

\section{Discharge and follow-up:}

The peritoneal drain was removed after 4896 hours if there was no bile leakage. Patients who had a T-tube inserted had a cholangiogram on the 10th post-operative day and if this was normal, the T-tube was clamped and the patients were discharged at 14th day. Patients with primary closure were discharged once the peritoneal drain was removed.

Follow-up assessment used abdominal ultrasonography, carried out at 3 months to 6 months in OPC, with MRCP or ERCP used when indicated.

\section{Results:}

Open choledochotomy was performed in 30 patients, out of which 15 had primary closure of CBD after stone removal (groupI) and Ttube drain was placed in 15 patients (groupII). The mean age of patients who had primary closures (groupI) was $45 \pm 15$ (range from 2570 years) and that of T-tube drains (groupII) was $(42 \pm 20)$ (range from 30-70 years).

There were 5 males $(33.3 \%)$ and 10 females $(66.7 \%)$ in group I.

There were 2 males $(13.3 \%)$ and 13 females $(86.7 \%)$ in group II. 
Table (1): Comparison between both groups as regard general data.

\begin{tabular}{|l|c|c|c|}
\hline Variables & $\begin{array}{c}\text { Group I } \\
\mathbf{N = 1 5}\end{array}$ & $\begin{array}{c}\text { Group II } \\
\mathbf{N = 1 5}\end{array}$ & P \\
\hline Age(mean \pm SD) & $45 \pm 15$ & $42 \pm 20$ & $>0.05$ \\
GS \\
Male & $5(33.3 \%)$ & $2(13.3 \%)$ & $>0.05$ \\
Female & $10(66.7 \%)$ & $13(86.7 \%)$ & NS \\
\hline
\end{tabular}

The clinical presentation of choledochlithiasis is listed in Table(2). Most of the patients in both groups presented with jaundice $(40 \%$ and $53.3 \%$ ) other clinical presentations were biliary colic and acute cholecystitis, which were nearly of same frequency in each group. Out of 30 patients, eight patients had comorbidities like diabetes mellitus and hypertension (20\% and $33.3 \%)$. 14 patients $(93.3 \%)$ in group I had concomittent gall stones and 12 patients (80\%) in group II as evident by preoperative abdominal ultrasonography.

Preoperative abdominal ultrasound also, showed the diameter of CBD, which was then confirmed during the operation.

The mean diameter of CBD was $1.6 \pm 0.6$ (range $1.2-2 \mathrm{~cm}$ ) in patients group I and the mean diameter of CBD was $1.54 \pm 0.3$ (range $1.5-2.2 \mathrm{~cm}$ ) in patients group II.

Table (2): Comparison between both groups as regard clinical presentations.

\begin{tabular}{|l|c|c|c|}
\hline Variables & $\begin{array}{c}\text { Group I } \\
\text { N=15 }\end{array}$ & $\begin{array}{c}\text { Group II } \\
\mathbf{N = 1 5}\end{array}$ & P \\
\hline Biliary colic & $4(26.7 \%)$ & $6(40 \%)$ & $>0.05 \mathrm{NS}$ \\
\hline Acute cholecystitis & $3(20 \%)$ & $3(20 \%)$ & $>0.05 \mathrm{NS}$ \\
\hline Jaundice & $8(53.3 \%)$ & $6(40 \%)$ & $>0.05 \mathrm{NS}$ \\
\hline Comorbidities & $3(20 \%)$ & $5(33.3 \%)$ & $>0.05 \mathrm{NS}$ \\
\hline Concomitant gall stones & $14(93.3 \%)$ & $12(80 \%)$ & $>0.05 \mathrm{NS}$ \\
\hline Common bile duct diameter (mean+SD) & $1.6 \pm 0.6$ & $1.54 \pm 0.3$ & $>0.05 \mathrm{NS}$ \\
\hline
\end{tabular}

There is no statistically significant difference between both groups as regard clinical and comorbid data.

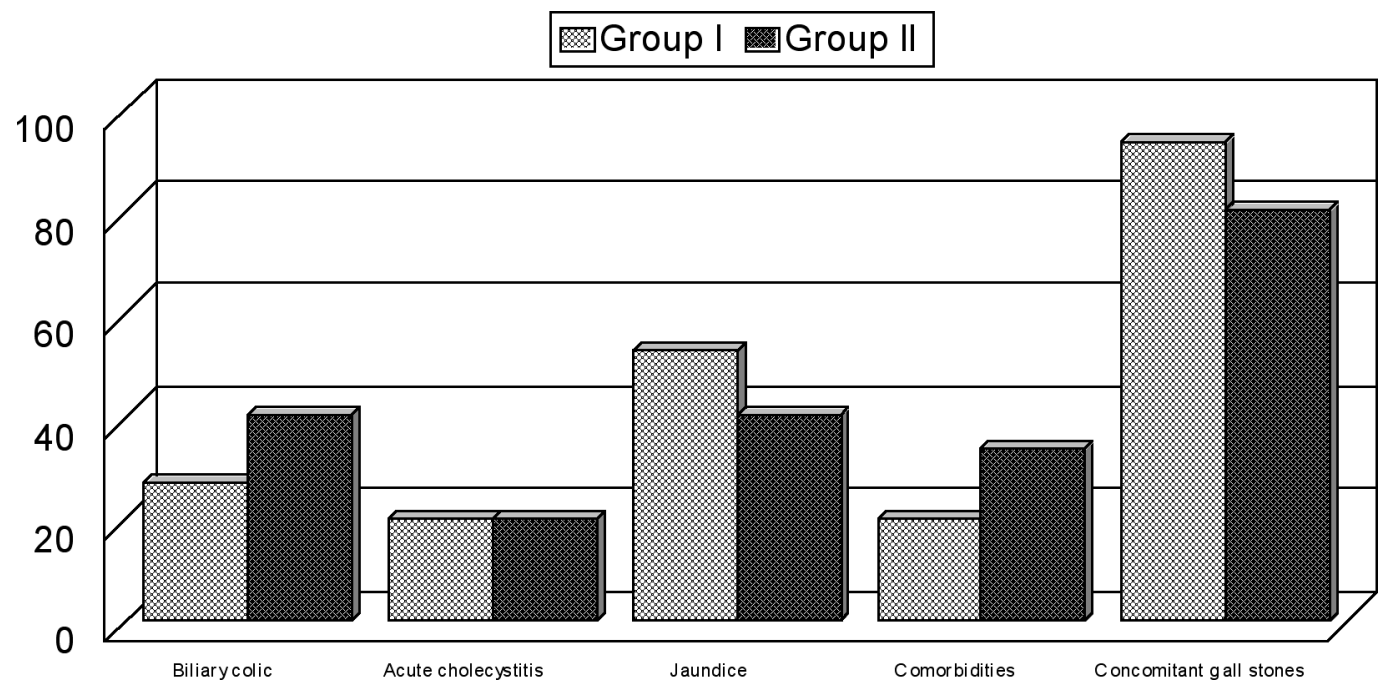




\section{In group I:}

13 patients did not suffer any complications. One patient had bile leakage that subsided on the 4th postoperative day. There was no biliary peritonitis. One patient developed jaundice on the 3rd week with elevated liver enzymes and was diagnosed as halothane toxicity and jaundice gradually subsided.

The total complications rate in group I was $(13.3 \%)$.

\section{In group II:}

Two patients had bile leakage after removal of T-tube that was managed by ultrasound guided aspiration.

Three patients had postoperative jaundice because of blockage of the duct caused by Ttube. The T-tube was removed and jaundice gradually subsided.

There was not any retained stones of CBD seen up to 6 months follow-up and postoperative ultrasound findings were normal.

Table (3): Comparison between both groups as regard postoperative complications.

\begin{tabular}{|l|c|c|c|}
\hline Variables & $\begin{array}{c}\text { Group I } \\
\mathbf{N = 1 5}\end{array}$ & $\begin{array}{c}\text { Group II } \\
\mathbf{N = 1 5}\end{array}$ & $\mathbf{P}$ \\
\hline $\begin{array}{l}\text { Bile leakage } \\
(<100 \mathrm{ml} / 24 \mathrm{hrs})\end{array}$ & $1(6.7 \%)$ & $2(13.3 \%)$ & $\begin{array}{c}>0.05 \\
\mathrm{NS}\end{array}$ \\
\hline Jaundice & $1(6.7 \%)$ & $3(20 \%)$ & $\begin{array}{c}>0.05 \\
\text { NS }\end{array}$ \\
\hline Retained stone & 0 & 0 & - \\
\hline
\end{tabular}

There is no statistically significant difference between both groups as regard postoperative complications.

The mean postoperative stay in group I was $5.1 \pm 2$ compared to the group II which was $7.4 \pm 2.1$
The mean duration of follow-up in group I was $4.5 \pm 1.4$ months and in group II was $4.6 \pm 1.3$

Table (4): Comparison between both groups as regard hospital stay and follow up.

\begin{tabular}{|l|c|c|c|}
\hline Variables & $\begin{array}{c}\text { Group I } \\
\mathbf{N = 1 5}\end{array}$ & $\begin{array}{c}\text { Group II } \\
\mathbf{N = 1 5}\end{array}$ & P \\
\hline Hospital stay (days) & $5.1 \pm 2$ & $7.4 \pm 2.1$ & $<0.05 \mathrm{~S}$ \\
\hline Follow up (months) & $4.5 \pm 1.4$ & $4.6 \pm 1.3$ & $>0.05 \mathrm{NS}$ \\
\hline
\end{tabular}

There is no statistically significant difference between both groups as regard follow up duration, while hospital stay was longer among group II compared to group I with statistically significant difference in between by using unpaired t-test. 


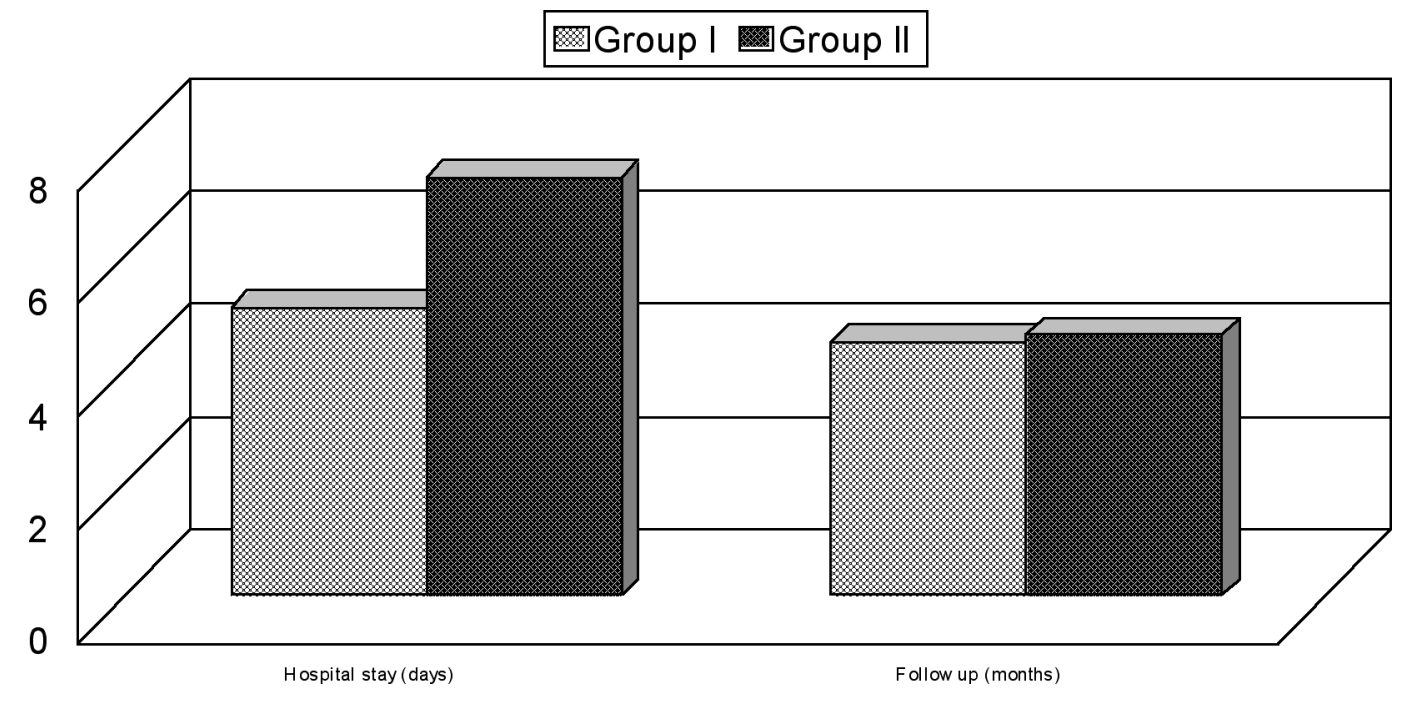

\section{Discussion:}

Traditionally, the CBD is closed with Ttube drainage after open choledochotomy and removal of CBD stones. However, the insertion of a tube is not without complications and the patients have to carry it for several weeks before removal.

The advocates of the use of a T-tube argue that is allows spasm or edema of sphincter to settle after the trauma of the exploration. Postoperative T-tube drainage has been used to prevent bile stasis, decompress the biliary tree, and minimize the risk of bile leakage, A T-tube also has provided an easy percutaneous access for cholangiography and extraction of retained stones. Despite these potential advantages, morbidity related to T-tube usage is reported to occur at a rate of $4 \%$ to $16.4 \%$

Accidental displacement of the T-tube, biliary leakage, duodenal erosion, persistent biliary fistula, excoriation of the skin, and cholangitis caused by micro-organisms migrating through the T-tube may prolong hospital stay and delay postoperative recovery.

In our study, we had two cases of bile leakages in patients in whom T-tube was used (group II) $(13.3 \%)$ and one case among the 15 patients $(6.7 \%)$ in whom primary closures of CBD was done (group I).

Yamazaki et al ${ }^{11}$ reported an incidence of
$11.7 \%$ and $5.8 \%$ respectively, and an overall incidence of leakage was reported to be $14.3-38 \%$. On the other hand, after primary closure, there were no bile leakage cases reported by other authors. ${ }^{12,13}$

In this study, no postoperative mortality occurred in either groups, and morbidity for both groups was similar.

Most complications in the T-tube group were related to the use of T-tube. Therefore, post-operative T-tube drainage is not necessary for decompression of the biliary tree. In addition, the use of intra-operative cholangiogram can also avoid overlooked biliary problems.

Our findings showed that primary closure did not increase the risk of bile leakage after operation.

Postoperative hospital stay and hospital expenses were lower in the primary closure group than in the T-tube group

\section{Conclusion:}

In open choledochotomy, primary clouse of CBD is performed safely and the use of intra-operative cholangiogram ensures clearance of the CBD and eliminated the need for T-tube. The hospital admission days are less, also the average cost of treatment is much lower. 


\section{References:}

1 - Hungness ES, Soper NJ: Management of common bile duct stones. J Gastrointest Surg 2006; 10: 612

2 -Ponsky JL, Heniford BT, Gersin K: Choledocholithiasis: Evolving intraoperative strategies. Am Surg 2000; 66: 262.

3 - Gharaibeh KIA, Heiss HA: Biliary leakage following T-tube removal. Int Surg 2000; 85: 57-63.

4 - Martin IJ, Bailey IS, Rhodes M, et al: Towards T-tube-free laparoscopic bile duct exploration: A methodological evolution during 300 consecutive procedures. Ann Surg 1998; 228: 29.

5 -Williams JAR, Treacy PJ, Sidey P, et al: Primary duct closure versus T-tube drainage following exploration of the common bile duct. ANZ J Surg 1994; 64: 823-826.

6 - Miguel Angel Mercado, Carlos Chan, Hector Orozco, et al: Bile duct injuries related to misplacement of "T tubes". Ann Hepatol 2006; 5: 44-48.

7 - Placer G: Bile leakage after removal of Ttube from the common bile duct. Br J Surg 1990; 77: 1075.
8 - Cuschieri A, Croce E, Faggioni A, et al: WEAES ductal stone study: Preliminary findings of multicenter prospective randomized trial comparing two-stage versus single-stage management. Surg Endosc 1996; 10: 1130.

9 - Mosimann F, Schneider R, Mir A, et al: Erosion of the duodenum by a biliary Ttube: An unusual complication of liver transplantation. Transplant Proc 1994; 26 : 3550.

10-Wills VL, Gibson K, Karihaloot C, et al: Complications of biliary T-tubes after choledochotomy. ANZ J Surg 2002; 72: 177.

11-Yamazaki M, Yasuda H, Koide Y, et al: Primary closure of the common bile duct in open laparotomy for common bile duct stones. J Hepatobiliary Pancreat Surg 2006; 13: 398-402.

12- Chen SS, Chou FF: Choledochotomy for biliary lithiasis: Is routine T-tube drainage necessary? Acta Chir Scand 1990; 156: 387-390.

13-Sorenson VJ, Buck JR, Chung SK, et al: Primary bile duct closure following exploration: An effective alternative to routine biliary drainage. Am J Surg 1994; 60: 451-455. 